\title{
The Role of Efficient Urban Governance in Managing Kuala \\ Lumpur City-Region Development
}

\author{
Hamzah Jusoh \\ Faculty of Social Sciences and Humanities, National University of Malaysia \\ 43600 UKM Bangi, Selangor Darul Ehsan, Malaysia \\ Tel: 60-3-8921-5683/5680Ｅ-mail: hj@pkrisc.cc.ukm.my \\ Jalaluddin Abdul Malek \\ Faculty of Social Sciences and Humanities, National University of Malaysia \\ 43600 UKM Bangi, Selangor Darul Ehsan, Malaysia \\ Tel: 60-3-8921-5683/5680Ｅ-mail: jbam@ukm.my \\ Azmizam Abdul Rashid (Corresponding author) \\ Faculty of Social Sciences and Humanities, National University of Malaysia \\ 43600 UKM Bangi, Selangor Darul Ehsan, Malaysia \\ Tel: 60-3-8921-5683/5680Ｅ-mail: azmizam67@yahoo.co.uk
}

\begin{abstract}
This paper discuss on the preliminary study on the concept of efficient in urban governance towards managing development of Kuala Lumpur City-Region. City-region development has been a major issue in the country's latest development agenda. The issue is more obvious in city-region due to its role as an engine of growth economy development. Now, with its sights set on attaining the economic level of a fully developed nation by 2020, Malaysia must focus on securing a credible share of the lead sectors of the globalised economy. Kuala Lumpur City-Region, which is the most developed region in the country and an important catalyst towards national economic growth. How well do urban governance responsible to efficiency and effectiveness of local authorities in city-region? What kind of urban governance is required to enhance competitiveness and earning opportunities within city-region? The main challenge of enhancing city competitiveness in city-region is efficient urban governance. The world today needs a new, comprehensive and holistic model of urban governance that involves all sectors (government, business and the civil society) as equal partners in development. Urban governance which integrates all sectors including public, private and other social organisations in participatory decision making. Efficient urban governance is characterized by sustainability, subsidiarity, equity, efficiency, transparency and accountability, civic engagement and citizenship and security. In line with this, the importance efficient urban governance would make Malaysia more competitive and attractive to investors and facilitate the achievement of the nation's development goals. Therefore Kuala Lumpur City-Region will manage and govern efficiently.
\end{abstract}

Keywords: Economic planning, Sustainable, Efficiency, Urban governance and city competitiveness

\section{Introduction}

Globalisation has escalated the level of competition in the international market. Not only does the domestic macroeconomic structure and environment need to be strengthened, but elements of the micro economy including the respective economic sectors and local corporations also need to be made more resilient. In order to enhance national long-term competitiveness, the Government will continue to promote the transition to higher value added activities in three main economic sectors, the first being manufacturing; second, services; and third, agriculture. New sources of growth in these sectors will be identified and promoted to generate additional income and to develop new sources of 
economic wealth. A major effect of globalization is the increasing competition between cities and regions on global scale. To facilitate economic development cities are forced to make they attractive for investors and enterprises by investing in infrastructure, facilities and the development of attractive sites for new business. City branding and the development of city-region play an important role in this framework. However, in particular these projects also have a reverse side-effect in regard to urban sustainability. In many cases they are contributing to fragmentation and segregation, they are socially exclusive and barely leave space for non-commercial activities. Drastic changes in society: fast urbanization, changes in the relation between the urban and the rural, globalization, economic changes and the need for more sustainable solutions for spatial problems - the themes of the other sessions in the conference - all lead to new urban forms or new forms of urbanism. The process of urbanization and urban transformation generates a new kind of spatial form that Castells is calling the metropolitan region: 'urban constellations scattered throughout huge territorial expanses, functionally integrated and socially differentiated, around a 'multi centered structure' (Castells 2005).

Sometimes these regions even are crossing the borders of nation states. For a long time it was expected that the increasing importance of regions would result in new (governmental) planning institutions which would be able to organize spatial development in a coherent way and to play a role in international competition. However, it seems to be difficult to translate the new regional reality into fruitful models of governance as well as into spatial structures which can provide a recognizable and attractive identity to the region. In contrary, most of these metropolitan regions are characterized by a lack of identity and citizen participation, by a weak political accountability and by the absence of an effective administration (Sassen 2001). On the other hand, the necessity of coordination on regional level causes new approaches of collaboration and new types of planning. The transformations in our cities and urban agglomeration triggered by globalization demand a review on the various planning cultures.

Each country must be prepared to act earlier, effectively and with high level of competitiveness. The need to drive the urban dynamic in an energetic responsible manner also demands an integral strategy with active participation of all stakeholders. The uncertainty and risks caused by climate change requires the adoption of preventive measures on the planning framework and new environmental regulations. The withdrawal of the state requires rethinking of the bottom-up approach process on spatial planning and careful analysis of its implications and potential. The processes of metropolization, the economic new parading of the regions and the functional urban networks open up questions on crossing border planning perspectives. The need to address global challenges in a strategic manner posses questions on the interplay between the local and the global. How a global strategy to deal with crossing borders challenges and climate change risks could fulfill the needs of a local governance role and cope with social problems? How these new challenges can be addressed in a coordinated manner among various stakeholders? What is the role of the citizenry?

The main purposes of this paper, thus, are to (1) discuss the background and necessity of urban governance in city-region; (2) review the composition and functions of efficient urban governance in development of city region; and (3) provide policy implications and government initiative to enhance development in Kuala Lumpur City-Region. Finally, some conclusions drawn with respect to efficient urban governance in enhancing competitiveness of Kuala Lumpur City-Region.

\section{Governance}

More recently, governance principles as propagated by global institutions such as the World Bank have tried to encourage grassroots participation in development projects and in local decision-making. Operating within patron-client frameworks, however, the increased involvement of non-governmental organizations (NGOs) and community-based organizations/peoples' organizations (CBO/POs) have had unintended, exclusionary effects. All over the world cities are searching for appropriate ways of governance in the context of far-reaching political, economic, social and institutional transformations affecting all levels of scale. These transformations are taking place with profound changes in networks and balances of power among stakeholders of the public, private and civil society sector. They trigger off the evolution of innovative strategies, procedures and instruments of how to coordinate, manage and govern urban development processes and stimulate the formation of new formal and informal actor networks.

Governance is not synonymous with government. This confusion of terms can have unfortunate consequences. A public policy issue where the heart of the matter is a problem of "governance" becomes defined implicitly as a problem of "government", with the corollary that the onus for "fixing" it necessarily rests with government. Since governance is not about government, what is it about? Partly it is about how governments and other social organizations interact, how they relate to citizens, and how decisions are taken in a complex world. Thus governance is a process whereby societies or organizations make their important decisions, determine whom they involve in the process and how they render account. Since a process is hard to observe, students of governance tend to focus our attention on the governance system or framework upon which the process rests - that is, the agreements, procedures, conventions or policies that define who gets power, how decisions are taken and how accountability is rendered.

These transformations are taking place with profound changes in networks and balances of power among stakeholders of the public, private and civil society sector. They trigger off the evolution of innovative strategies, procedures and 
instruments of how to coordinate, manage and govern urban development processes and stimulate the formation of new formal and informal actor networks. The United Nations Development Programme (UNDP) 1997 defines governance as the exercise of economic, political and administrative authority to manage a county's affairs at all level. It comprises the mechanisms, processes and institutions through which citizens and groups articulate their interest, exercise their legal rights, meet their obligations and mediate their differences. Governance opens new intellectual space. It provides a concept that allows us to discuss the role of government in coping with public issues and the contribution that other players may make. However, and table 1 shows a summary of definition of governance from a various scholars.

It opens one's mind to the possibility that groups in society other than government (e.g. 'communities' or the 'voluntary sector') may have to play a stronger role in addressing problems. The central conclusion is that a universal set of principles for defining good governance can be fashioned and that the strength of their universality rests to a large extent on the body of international human rights and laws. In addition, these principles can be usefully applied to help deal with current governance challenges. When they are applied it becomes apparent that there are no absolutes; that principles often conflict; that the 'devil is in the detail'; that context matters. Finally, the nature of governance - both the means and the ends - needs to be understood.

Only then does it make sense to elaborate the principles in order to create a meaningful analytical tool. Good governance is important for countries at all stages of development. Our approach is to concentrate on those aspects of good governance that are most closely related to our surveillance over macroeconomic policies-namely, the transparency of government accounts, the effectiveness of public resource management, and the stability and transparency of the economic and regulatory environment for private sector activity. In summary, governance can be defined as a process of breaking from the previous condition, where governments were centralized to promote a policy or project, to one in which a network is constructed by various actors - such as the government, state, market, and civil society. The prime characteristic of governance is respect for the autonomy of the participants and understanding of their interdependence. And it is a co-governing system, settling socially complex issues by co-operating in partnership networks and coming to consensus by adjusting affairs.

\section{Governance in an urban context}

As globalization and the information society have progressed rapidly since the 1980s, the role and function of the state, market, and civil society have changed. The functional power of the state and government has decreased, while the role of capitalistic markets has increased. During the same time, the character and range of participation of citizens and citizen associations, such as NGO and NPO, has expanded. Therefore, the concept of urban governance has gained the attention of many researchers in the last few years; it is often regarded as the opposite of traditional urban government. (Vranken et al., 2003). The Urban Governance Initiative (TUGI) of UNDP focused on nine principles of good urban governance which are: participation, rule of law, transparency, responsiveness, consensus oriented, equity, effectiveness and efficiency, accountability, and strategic vision.

In essence, urban governance is the integration of effort between the community, private sector and city-region authorities where the urban authorities perform the coordinating role and determine the quality of the microeconomic environment and location that is favourable attract investors and people. In most cases, the private sector provides the much needed financial assistance and business expertise to operate independently or in association with the public sector. The community provides the individuals who are employees, consumers or are beneficiaries of the governance process. Table 2 shows a summary of definition and application of urban governance.

A more integrative approach, one that goes beyond the boundaries of the different departments (inter-departmental cooperation), should replace this political system. Andersen and Van Kempen (2003) distinguish a number of changes that mark the shift from urban government to urban governance:

i. A replacement of universalistic policies by targeted policies.

ii. A growing use of covenants as policy regulation.

iii. An attempt to integrate policy fields from various departments into a unitary project organization.

iv. A focus on the empowerment of residents and of cities and specific neighbourhoods.

In summary, urban governance is strategies are achievable through the process integration all sectors including public, private and other social organisations. To accomplish the desired outcome, this integration results in an effective and efficiently managed city. Thus it contributes to economic development, stabilization and welfare, bringing the transparency of decision-making process, social participation, openness, finance equilibrium and law being obeyed to. Integrated mechanisms, processes and institutions, through which citizens and social groups might state their 
preferences, negotiate solutions of their contradictions and make use of their constitutional rights, as well as realize their duties, is also being understood as the urban governance.

\section{Efficient urban governance}

Simon (1976) proposed in its broadest sense, to be efficient simply means to take the shortest path, the cheapest means, toward the attainment of the desired goals. However, efficiency is not limited simply to making incremental efficiency improvements in existing practices, but it should stimulate creativity and innovation in the search for new ways of doing things. In this context, cities must be financially sound and cost-effective in their management of revenue sources and expenditures, the administration and delivery of services, and in the enablement, based on comparative advantage, of government, the private sector and communities to contribute formally or informally to the urban economy. Communities and Local Government Department of United Kingdom, 2006 defined efficient local government is about raising productivity and enhancing value for money. Efficiency gains are achieved by one or more of the following:

i. Reducing inputs (money, people, assets etc) for the same outputs;

ii. Reducing prices (procurement, labour costs etc) for the same outputs;

iii. Getting greater outputs or improved quality (extra service, productivity etc) for the same inputs;

iv. Getting proportionally more outputs or improved quality in return for an increase in resource.

Therefore, the aim of the efficiency in urban governance is to ensure that the resources available to local government are used in the optimum way to deliver better public services according to local priorities. An efficient urban governance system should be established to administer urban growth and development at various levels particularly at the local authority level. This will ensure that the value of assets, economy, social and the environment will be maintained and value-added towards attaining sustainable development in Malaysia. The local authority, as the main agency responsible for urban management, needs to update the administration and management system to optimize its financial revenue including new sources, upgrade its capacity-region to enable towns to become more competitive and viable, strengthen human resources by employing skilled and experienced staff as well as expand the use of technology.

With rapid urbanisation, local authorities should emphasize the use of innovative approach and technology to reduce cost and increase efficiency in all aspects of urban planning, development and management. In addition, these efforts will contribute to the management of a more viable environment. The management and administration system practised should be founded on an ethical work culture, be transparent and efficient to ensure a more effective delivery system. In this light, there is a need to review and strengthen the respective system and work procedure, implementation approach, standards and guidelines to achieve the highest standard of services. To complement actions being carried out, the existing legislations related to urban administration and management should be reviewed for a more effective enforcement and implementation of the urban development. Local authorities need to cooperate closely with the local community, non-governmental organizations and the private sector to plan and implement appropriate urban planning and management programmes that meet with their requirements for sustainable development as mooted in the Local Agenda 21.

Such cooperation will provide opportunity for the local community to monitor and give feedback on the programmes implemented in their respective area. To facilitate this proposal, the local authority should establish a unit responsible for coordinating and managing programmes to improve local community participation in urban planning and governance activities. Efficient urban governance consider economic and environmental aspect are in an integrated manner. It should supported by the community which believes that the importance of and is committed are changing the unsustainable behaviours. The efficient urban governance focus to achieve a better integration between transport and land se aspect in protecting the strategic transport corridors at the regional level while implementing local integration at the community level.

The efficient urban governance also emphasis non-polluting transport, for instance walking and cycling which this elements are supported by a physical urban form to sustain these modes. The greater emphasis of the efficient urban governance is placed on recycling and waste reduction programs. Together, we must establish urban governance discourse in order to implement the principles of transparency and accountability; and respect and fairness in the public dialogue.

\section{Efficient urban governance as an asset of city-region}

According to the Institute on Governance one simple definition of governance is 'the art of steering societies and organisations'. The ability to make these decisions relies on city-region actors to delegate a large portion of the decision-making responsibility to this entity. However, it is a little more complicated than this. Steering suggests that governance is a straightforward process, akin to a steersman in a boat. But by its very nature, governance is complicated 
by the fact that it involves multiple actors, not a single helmsman. These actors are important because they articulate their interests; influence how decisions are made, who the decision-makers are and what decisions are taken. They feed into the decision-making process, but the decision-makers are then accountable to those same actors for the output, and process for producing it.

The aim of governance the taking of decisions and rendering of account-is good governance. Here the desired results are achieved and achieved in the right way. Just as much as bad governance can be a major barrier for city-region, good governance can be a key asset for a city-region looking to elevate its position in the national and international competitiveness league tables. There is, however, no universal template for good governance in city-region. Instead, each city-region- region must tailor its definition of good governance to suit its needs and values. What is right for one city-region will not be right for another. This goes some way to explaining why city-region across the world operate through a variety of different governance models.

Before looking at the various city-region al governance models, it is first necessary to highlight a number of key principles which underpin all examples of good governance. According to the United Nations, good governance has nine major characteristics. This is not a prescriptive model for good governance; rather it is a series of aspirations. Each city-region will be stronger on some aspirations and weaker on others. This depends on their governance model, but moreover, it depends on the negotiations that take place between the multiple actors who have a stake in that city-region. To understand how city-region develops different governance models despite pursuing the same aspirations, we must recognize that city-region is a site of contest, tension and conflict. Although many of the actors are the same across city-region, we must also recognise that their role and, more importantly, their authority will be different in each.

One prominent example of this would be the state. An important actor in any city-region, the degree of authority a state has over the city-region can dictate the nature of the governance model and to a large extent its success in meeting the aspirations of good governance. All other actors contribute in however small a way to the prevailing governance model and its success. As a consequence, there is no one model for the governance of city-region. Rather there are a number of models, any number of which can be found in close proximity to one another.

The very nature of the media frenzy which surrounds their election to office, and their capacity-region to change the very nature of the city-region (for example, the introduction of 57 the congestion charge in London) ensures that the leader becomes a figurehead under this model of governance. Appropriate for global city-region where, in political terms, there is legitimacy for such a formal tier of city-region al governance, it is questionable whether this model of governance is practical and/or achievable for other cities. Compare the US with the UK for instance. While the federal nature of us government sees power divided between central government and the government of each state, the centralised nature of UK politics sees London as the only city-region currently operating with this formalized model of governance.

Here UK city-region operates through less formal governance structures. Still operating above local authorities, these city-region al governance bodies range from the still quite formal, where group members are all directly elected, to institutions where members are either appointed or indirectly elected. Below this, the most informal model of city-region al governance sees the formation of metropolitan area boards - a voluntary collaboration between local authorities. As well as ranging from the formal to the informal, we can also relate models of city-region al governance ranging from 'strong' to 'weak'. Naturally the most formal models of city-region al governance are the most likely to have statutory status, legislative powers, and additional tax raising powers. So what dictates how formal and strong or informal and weak a city-region model of governance is? As intimated earlier in this chapter, the complexity which surrounds models of city-region al governance derives from the interest conflicts of the actors involved and the differences in legitimacy they share. Central to the outcome is the negotiation of interests between the city-region and national government (DCLG, 2003).

\section{Kuala-Lumpur city-region}

Christaller's city-region as described in 1933 Central Place Theory, focused on local, hierarchical urban-hinterland relations that have now been overtaken by the processes of economic globalization previously discussed. In common with other early location and systems theories, central place theory was a relatively static model which emphasised core-periphery relationships between cities and their surrounding hinterlands. But as Peter Taylor's work has shown, in modern-day globalisation, a city's development is less linked to its nearby hinterland than to a far-reaching global 'hinterworld'. As explained, cities are now integrated into a world city network of informational flows, knowledge and economic exchange as opposed to the national and regional scales of interaction prioritised in Christaller's pre-globalisation model.

With the development of knowledge-dependent forms of commercial production and trade in a world economy, the economic relations of city-regions can clearly no longer be defined in this way. The new reality of a borderless space economy suggests the need to find a new term to describe the intersection of global flows with the city-region scale. 
The term, the global mega-city region used in the polynet study, thus builds on Allen Scott's 2001 notion of the economically developed global city region and that of the mega-city region associated with urban expansion in poor economies of the developing world. City Region - an extensive and functionally interconnected cluster of urban centres that is developing around the world's major cities. This phenomenon is arising in a number of distant locations in parallel with a major shift in global economic relations as capital moves from the developed to the less developed world.

In short, the macroeconomic changes that are occurring as nation states worldwide open up to direct foreign competition and embrace the post-industrial global economy are also impacting on a local scale around cities that are gateways for the new wave of globalisation. These unprecedented global and local changes present major challenges for the nation state in two ways. On the one hand, increasing integration and informationalisation of the world economy is challenging the power and authority of states over long established national jurisdictional territories; on the other hand, the dramatic impacts of global change at a city region scale seem to require urgent mediation. The National Physical Plan (NPP) is a long term national level plan for the period until 2020. NPP spells out policies that determine the direction of physical development and conservation areas within Peninsular Malaysia.

The main goal of the NPP is to create an efficient, equitable and sustainable national spatial framework to guide the overall development of the country towards achieving a competitive developed nation status by the year 2020. NPP defines Kuala Lumpur-Klang Valley-Seremban areas as the National Growth Conurbation (Kuala Lumpur City-Region) which effectively covers an area of approximately 504,000 hectares and is to provide for a potential population of 8.5 million or $32 \%$ of the Peninsular Malaysia population by 2020. This means that the premier city of Kuala Lumpur's regional population is more than seven times Kuala Lumpur's population of 1.4 million (2005). The strong regional population base will enhance Kuala Lumpur role as an International Regional Commercial and Financial Centre. Thus the Kuala Lumpur City Plan 2020 (KLCP 2020) will be a flexible document; one that is attractive to investments, able to accommodate new economic activities as well as cater for the increasing job opportunities in the city. Kuala Lumpur City will be the key beneficiary to the NPP's regional strategy. Regional linkages via rail to Johor Bharu and George Town conurbation will further strengthen Kuala Lumpur's position and the vision for World Class City becomes more significant in the local context of the NPP.

\section{Issues of Kuala Lumpur city-region development}

\subsection{Rapid rate of urbanisation}

Urbanisation in Malaysia has developed rapidly especially during the last two decades whereby the rate of urbanisation has increased from $54.3 \%$ to $65.4 \%$ between $1991-2000$. This is expected to increase to $75 \%$ by 2020 . The increase in population will mostly concentrate in major conurbations such as Kuala Lumpur City Region, Georgetown, Johor Bahru and Kuantan. The high rate of population increase requires the development of new areas for housing, social amenities, commercial and other urban land uses. The lack of clear urban limits has led to the creation of urban sprawl encroaching upon environmentally sensitive areas, major agricultural areas and areas unsuitable for development.

In addition, non compliance with the existing development plans has also contributed to this problem. This situation has given rise to various urbanisation related woes such as environmental pollution, traffic congestion, brown field areas, loss of inner city attractions, infrastructural decay, lack of social amenities and green areas; ultimately resulting in degradation in the quality of urban living. The problem of conflicting land use still exists especially in towns that experience rapid growth considering the high demand of land use at strategic areas. The existence of illegal factories in urban areas has caused much environmental pollution.

\subsection{Ineffective urban governance}

National Urbanisation Policy of Malaysia proposed with the rapid pace of urbanisation by 2020, urban governance is faced with various complex challenges a head. These challenges require that the respective parties be more focused in undertaking parties be more focused in undertaking each and every responsibility in urban development. However, the involvement of multiple agencies and departments in urban management had made it difficult to coordinate many actions and in turn affects the effectiveness of those actions. Good urban administration and management also need to take into consideration the capability of each local authority as each local authority as each differs in terms of manpower, skills and financial capacity to provide good service for its population. There is wide gap between the expectation of the community and the ability of the local authority to fulfil those expectations.

The various roles that are expected of these local authorities to attain a liveable city with a high quality of living had put pressure on those authorities to acquire a strong organisation. The pressure is left more intensely by small; and medium sized local authorities that lack finance, manpower, skills and equipment in providing the expected services. The local authority is also confronted with the diverse aspirations and interests of community groups that it has to fulfil, as well as various social issues and negative influence. Public cooperation and involvement are much needed to address these problems. However, community participation that are too brief pertaining to activities organised by the local authority 
also inhibit and do not fulfil that aspiration of the local authority at involving the community in planning and development of urban areas.

\subsection{Less competitive urban economy}

The United Nations forecast that $60 \%$ of the world population which is equivalent to five billion people will reside in urban areas by 2030. With more than three quarter of the population living in urban area in Malaysia by 2020, the demand for employment in urban centres will significantly increase. This will put a pressure to create enough employment in urban areas to meet the increasing demand as well as reduce unemployment to an acceptable level. A high unemployment rate will result in various social issues related to poverty, crime and nuisance. The pressure to create employment will be more intense in the conurbation which is expected to encounter competition from other cities worldwide due to globalisation and trade liberalisation. This is because the conurbation is anticipated to lead the nation in securing foreign investment, and in turn become competitive centre to attract investors. Thus, one of the challenges of the urban economy is turn urban areas into investment and commercial centres. It should have the capacity to attract foreign and local investment and trade in order to achieve a viable economy and provide adequate employment opportunities.

\subsection{Inefficient transportation system}

The Road and Transport Department of Malaysia stated that the total number of registered vehicles for Malaysia was 14.8 million in 2003. Out of this, $47 \%$ comprised of motorcycles, $44 \%$ were private cars while the remainder were commercial and other vehicles. The large number of private vehicle ownership puts pressure on the capacity of the existing road network especially for larger conurbations like Kuala Lumpur City Region and Georgetown. Furthermore, inefficient public transportation resulted in the tendency for the urban population to opt for private vehicles instead of the public transport. Study on the Integration of Public Transport Development and Land Use in Klang Valley 2003 the ratio of private vehicle usage compared to public transport was 89:11.

These two factors have contributed to the acute problem of congestion in those cities. In the long term, this will have negative impact on the competitiveness and the attraction of those cities to draw local and foreign investors. Basically, the current transportation system is insufficient to handle the problem of congestion and provide services incorporated with safety and user-friendly principles to the urban dwellers. Transportation facilities are provided without taking into account the need to integrate the different modes of transportation subsequently make it difficult for the user to change the modes of transportation. The provision of physical infrastructure for public transportation system such as covered pedestrian footpath and bus stops that enhance the comfort of the user.

\subsection{Declines in quality of living for urban dweller}

The decline in quality of living in urban areas is one of the major issues that arise out of poor management of urban development. For a town to be both viable and sustainable it is necessary to provide quality support infrastructure and a high quality of living derived from the provision of adequate housing, education, recreation and health facilities. In respect of the provision of housing, the main issue is the lack of housing for the low income group. Although the supply of housing is generally in excess of actual demand, the supply of housing for the urban poor is still insufficient as the price of these houses is beyond the reach of this group.

In terms of social facilities, it was found that the provision of recreation areas is generally inadequate for all towns in Malaysia. Moreover, there is a problem of maintenance of facilities as well as being non-user friendly since the location and design of facilities do not take into account the needs of certain segments of the society such as the disabled, children and elderly. Vandalism of public properties also exists and leads to not fully utilised facilities. The rapid growth of the urban population has also increased the demand on infrastructure and utility which is beyond the capacity of the existing facilities. In terms of the quality of urban services provided, it is generally beset by a low level of service incapable of fulfilling the urban dwellers expectations. Figure 2 shows the spiral effect of inefficient urban governance in Kuala Lumpur City-Region development.

\section{The improvement of efficient urban governance in Kuala Lumpur City-Region development}

Local authorities are the nucleus of the society it serves. Sometimes it may be a fair reminder to return to basics and ask questions of the nucleus concept in societal development. Local authorities form the very essence of service delivery, where the rubber meets the road. Local authorities are the front face of the public service and you bear the duty of carrying that brand effectively. It is towards this end that Public Service of Malaysia has today introduced, for the first time in Malaysia, the ethos of place branding. Place branding takes local authorities back to the basics of: i) reputation is what they build by how they run the place; ii) delivery standards are derived from the promises we deliver to our stakeholders; and iii) Consistency is service delivery efficiency.

It is in this context that government are engaging all local authorities at city, district and municipality levels to essentially deliver one message - "Deliver on our promises, and deliver them with consistency". It is in this context too that 
government spelled out in the Public Service Commitments 2008 that civil servant of "I know what is good for you", no longer works. Success is jointly driven by all parties who claim that success. For a place, it has to be by those who claim a stake and interest in that place.

Under urban governance concept, local authorities shall going back to basics to deliver the very the essence of efficient service especially related to property development such as i) partnership and collaboration in service delivery; ii) effective communication comes from effective information gathering, failing which will compromise the reputation of our Local Authorities. Thus the places they manage; iii) appreciate the far reaching effects of perception when not managed well; and iv) formulate, execute and monitor action plans. An efficient and effective public delivery system can only emanate from inclusive collaboration of all stakeholders. We will keep to this winning formula and build on the strength of this collaboration going forward. However, in era of globalisation, the government has initiated to enhance efficient urban governance in Kuala Lumpur City-Region development such as:

\subsection{Engaging the private sector}

First, local authorities in Kuala Lumpur City-Region are actively engaging the private sector to come up with measures to support the business community in these difficult times. To be effective, the measures the local authorities in Kuala Lumpur City-Region want to put in place cannot be drawn up in a vacuum. It is a given that even in the best of times local authorities in Kuala Lumpur City-Region and the business sector must collaborate and cooperate if the measures are to be meaningful and effect the changes planned. All local authorities in Kuala Lumpur City-Region are engaging their stakeholders to get feedback and proposals to forward to the Economic Council, a committee which is chaired by our Prime Minister. In many ways local authorities in Kuala Lumpur City-Region has had a head-start in the way public and private sectors have been engaged.

If we can recall in 1983, realising the benefits that the country can derive from such close cooperation, the Malaysian Government introduced a new concept in its vocabulary of national development, and that is, "Malaysia Incorporated". This concept has evolved from one of strategic intent to an operational reality. This has forged a national consensus that economic development was not just a public sector responsibility. The private sector too has an equally important active role in local authorities in Kuala Lumpur City-Region's development. This was somewhat radical when it was first articulated. The local authorities in Kuala Lumpur City-Region as public sector have always been under close scrutiny. It cannot be denied however, that despite the criticisms, complaints and short-comings, we cannot trivialise the role of the public sector in national development.

We have seen this role evolve from that of initiator and implementer of economic plans to that of facilitator of economic growth, to being a partner with the private sector in nation building although in the last few decades, the private sector had been the engine of growth. In the current economic situation, the public sector assumes an even more important role; what the our Prime Minister refers to as the "Engine of Economic Recovery". While no one will argue with the value of private-public engagement, its success depends a great deal on the ability of both sectors to establish and maintain a relationship based on the spirit of cooperation, mutual understanding and consensus. The private sector must understand the policies, objectives, rules and regulations as well as systems and procedures of the various Government agencies in local authorities in Kuala Lumpur City-Region it deals with. The local authorities in Kuala Lumpur City-Region must, on the other hand, be sensitive to the needs and goals of the private sector and has a duty to ensure no undue hindrance is put in the way of the private sector. Today, the spirit of Malaysia Incorporated is alive and well and is exemplified in PEMUDAH, the Special Task Force to Facilitate Business. Established by the Prime Minister 2 years ago, on 7 February 2007, PEMUDAH embodies the inclusive mechanism so essential for improving the effectiveness of the public sector delivery system, and by extension, national development.

\subsection{Speedy implementation of measures}

Second, besides engaging the private sector in drawing up measures for the stimulus package, the public sector is working to ensure the speedy implementation of these measures. For, clearly, it is one thing to have a stimulus package, but it is quite another to ensure its effective implementation. All local authorities in Kuala Lumpur City-Region responsible for the implementation of projects under the stimulus package have to report the progress regularly to the Economic Council and to Cabinet. The current economic situation requires not only rapid and effective response from the civil service, but more importantly it requires that the public sector members and the Government as a whole work closely with the business community and civil society to ensure timely implementation of the measures.

\subsection{Review processes, procedures, rules and regulations}

Third, all local authorities in Kuala Lumpur City-Region are reviewing existing processes and procedures, rules and regulations, in order to improve the local authorities in Kuala Lumpur City-Region delivery system. Even as we focus on implementation of the stimulus package, we will continue to improve public service delivery, because this ultimately translates into reducing the cost of doing business, facilitating business, increasing transparency and speedier delivery of service. In this regard the public-private sector engagement through PEMUDAH has been effective in contributing to 
improvements in the public delivery system. This will continue until we get to the point where the PEMUDAH spirit is prevalent and can be taken for granted; and where the process of inclusive engagement becomes second nature to both the members of the civil service and private sector. To emphasise the point that we cannot only hold the public sector or local authorities in Kuala Lumpur City-Region responsible for the implementation of the measures that we have put in place.

For local authorities in Kuala Lumpur City-Region to make it through this difficult period, the private sector must also contribute. Example, when the public service made the commitment to make payments within 14 days, local authorities in Kuala Lumpur City-Region assumed that the main contractors will cascade similar payment terms to their partners. However, they find that this is often not the case with the result that sub-contractors unfairly blame the local authorities in Kuala Lumpur City-Region for late payment, when the fault lies with the main contractors, who despite benefiting from the improvements made by the public sector, has not passed it on to his suppliers or sub-contractors. For the whole system to work efficiently and effectively, all parties must complement and reciprocate each other's efforts and improvement initiatives. The private sector can also work with local authorities in Kuala Lumpur City-Region, by not only contributing ideas on what local authorities in Kuala Lumpur City-Region should do, but also, by focusing on increasing efficiency and productivity, retaining residents in Kuala Lumpur City-Region talent, skills and workers, and look at reducing the cost of our services.

For example, on the prompting of PEMUDAH, last year, the Malaysian Institute of Chartered Secretaries and Administrators, or MAICSA, has agreed to reduce the charges for incorporating a company from about RM3,700 to RM2,800 and annual corporate fees from about RM1,850 to RM1,200. There will be no letting up in the drive to improve public service delivery. Measures of relevance to the private sector include:

i. First, the local authorities in Kuala Lumpur City-Region will leverage on technology to deliver with speed, clarity and transparency. This is already being put in place. The myGOVernment portal will mean that service is delivered via a single window. There will no longer be the need for the customer to go from department to department to get the service required. Given the level of ICT-savvy of the Malaysian public, the public sector must deliver more services on-line, with the option of equally effective counter-service for members of the public who may not be e-ready.

ii. Second, there will be greater inter-agency dialogue and communication in the way work is done, decisions made and problems solved. The "One Service, One delivery, No Wrong Door" is not only a mantra. We shall work to make it a given. What this means for the private sector is that, cases of being given the run around will become history.

iii. Third, there will be greater integration of processes, with high levels of information sharing. For the private sector and the man-in-street this means that there will be no need for repeated requests for information. Also, there will be increased replication of best practices of processes, procedures and effective systems to shorten the learning curve and optimise use of resources.

We believe the years ahead the competition will only get more intense and new challenges will emerge, emanating from the entry of new players, more challenging economic environment, new rules in the trading arena and the like. When we engaged the World Bank "Doing Business" team late last year we were informed that new indicators were being formulated to include aspects like corruption and transparency. These are issues that the Government is also focused on as exemplified by the establishment of the Malaysian Institute of Integrity. Domestically new challenges have also emerged and the civil service will need to interface with new models of Government to ensure that businesses and citizens continue to benefit from the improved delivery of government services. Coping successfully with these changes is a priority for the civil service. We are of the view that local authorities in Kuala Lumpur City-Region is well placed to take on the new challenges alongside the old ones, and in the process move to a higher level of service to facilitate the continued growth and expansion of businesses and the economy.

In moving the economy forward local authorities in Kuala Lumpur City-Region would like to reiterate that we will continue to work in close collaboration with the private sector. The frankness and intensity of exchanges between the private and public sectors, and the feedback local authorities in Kuala Lumpur City-Region have received at PEMUDAH have been helpful in identifying and addressing the issues closest to the heart of businesses. Perceptions or misperceptions about the way local authorities in Kuala Lumpur City-Region operate have also been addressed in PEMUDAH, and on the advice of our private sector partners we will focus on enhancing our media communications programmes and the way we engage stakeholders.

In the coming year, PEMUDAH will work on issues that are not only directly but indirectly related to the property market and business environment. We will be looking to address environmental issues that directly impact on the friendliness of our places, land matters which have a bearing on setting up business and homes, and feeding our populace; review the approach to the employment of foreign labour coupled with development of domestic human resource and skill upgrading; and branding our towns and cities to have a positive impact on local authorities in Kuala 
Lumpur City-Region competitiveness and tourism. Local authorities in Kuala Lumpur City-Region will also work in relation to government procedures and processes, making it more transparent and accountable. In the areas of doing business, work will continue to be focused on trading across borders, registering property, taxes, enforcing contracts and closing a business.

As mentioned before, the focus will also be on serving the citizens better. In this regard local authorities in Kuala Lumpur City-Region welcome civil societies comments and proposals which they can channel through the PEMUDAH website. They value such interaction, and look forward to inputs on how local authorities in Kuala Lumpur City-Region can serve citizens from all walks of life more effectively and with a difference in the quality of outcomes. The business competitiveness is a function of efforts of both the public and private sectors. The level of competitiveness attained by our nation is dependent on whether both parties have contributed meaningfully to the process. Looking back at local authorities in Kuala Lumpur City-Region's development and the path they have taken, it can be said that they have done many things right to have arrived where we are as a nation. However, the questions that beg to be answered are whether they could have done more, and is it going to be enough to remain competitive moving forward? Kuala Lumpur City-Region is sure that they will agree that competitiveness re-defines itself on a daily basis, and to take anything for granted would be to leave our future to chance. The bottom line is that Kuala Lumpur City-Region has to keep running the race and keep looking over our shoulder to see who is catching up, even as local authorities in Kuala Lumpur City-Region look forward to overtake the competitors ahead.

\subsection{An efficient and sustainable urban development}

Urban development should have a clear guidance on the direction of future expansion to accommodate an orderly and manageable development. The development of an urban system needs to be based on clear system of hierarchy so that the provision and distribution of facilities and infrastructure will be more efficient, thus, preventing wastage of national resources. Urban development needs to be carried out within a specified area to ensure urban sprawl is avoided. Towards this end, land use development should be based on the adopted development plan and comply with all policies, programmes and action plans proposed by the respective plan.

The urban limit needs to be identified to implement the development of a more efficient land use. Urban development should be implemented in accordance with the principles of smart growth with emphasis on redeveloping suitable areas especially in urban centres and brown field areas, preserving green areas for recreational purpose and conserving environmentally sensitive areas. This is to prevent development from encroaching upon agricultural and environmentally sensitive areas, to promote the optimum usage of existing infrastructure and to revive the attractiveness and liveliness of the urban centres. Urban redevelopment programme of suitable and strategic areas in one way of increasing the efficiency of urban areas.

\subsection{Effective and efficient urban governance}

An effective urban governance system should be established to administer urban growth and development a various levels particularly the local authority level. This will ensure that the value of assets, economy, social and the environment will be maintained and value-added towards attaining sustainable urban centres in Malaysia. The local authority, as the main agency responsible to urban management, needs to update the administration and management system to optimise its financial revenue including new sources, upgrade its capacity to enable towns to become more competitive and viable, strengthen human resources by employing skilled and experienced staff as well as expand the use of technology.

With rapid urbanisation, local authorities should emphasize the use of innovative approach and technology to reduce cost and increase efficiency in all aspects of urban planning, development and management. In addition, these efforts will contribute to the management of a more viable environment. The management and administration system practised should be founded on an ethical work culture, be transparent and efficient to ensure a more effective delivery system. In this light, there is a need to review and strengthen the respective system and work procedure, implementation approach, standards and guidelines to achieve the highest standard of services.

To complement actions being carried out, he existing legislations related to urban administration and management should be reviewed for more effective enforcement and implementation of the urban development. Local authorities need to cooperate closely with the local community, on-governmental organisations and the private sector to plan and implement appropriate urban planning and management programmes that meet with their requirements for sustainable development as mooted in the Local Agenda 21. Such cooperation will provide opportunity for the local community to monitor and give feedback on the programmes implemented in their respective area. To facilitate this proposal, the local authority should establish a unit responsible for coordinating and managing programmes to improve local community participation in urban planning and governance activities. 


\subsection{Development of an urban economy that is resilient, dynamic and competitive}

There is a need to identify the economic strength and specialization of each urban centre to develop, promote and strengthen its future growth and development. A strong correlation between economic growth and urban growth further clarifies the role of the local economic base in national economic growth. A major conurbation will encounter challenges from globalisation and technological development including the emergence of knowledge-based economy. The growth of knowledge-based economy requires a high level of competency among administrators, service providers and consumers. The improvement of skills of the urban dwellers will further accelerate economic growth, expand knowledge, and lead to the upgrading of skilled manpower.

Besides encouraging the growth and development of major urban centres, the economic development of medium and small sized urban centre should also be supported as they provide consumer goods to the urban population. Small towns also have an important role in improving the standard of living of the rural population as they function as commercial and trading centres especially in marketing agricultural products. The growth of these small towns creates demand for agricultural products and provides non-agricultural employment opportunities; both of which will improve the economic base of the rural population.

\subsection{An integrated and efficient urban transportation system}

An efficient and comprehensive transportation system is vital in enhancing the competitiveness of an urban centre. The increase in population and high private vehicle ownership compound by an inefficient public transport calls for a strategy that could resolve these issues. Thus, the development of an integrated transportation system needs to be implemented with emphasis on multi-modal and environmentally friendly features to address the problems of congestion in large cities like Kuala Lumpur City Region, Georgetown and Johor Bahru Conurbations. A policy that promotes the use of an integrated public transportation system that is effective and affordable to all levels the population should be formulated. Furthermore, traffic management has to be implemented comprehensively in order to reduce congestion in the cities.

\subsection{Provision of urban services infrastructure and utility of quality}

The provision of infrastructure and utility should be viewed in terms of fulfilling the demand of the population and supporting the growth of the urban economy as well as contribute to the competitiveness of the particular township. Infrastructure and utility need to be adequately provided in terms of quality, coverage of distribution, and be of high quality that utilizes the latest technology. The provision of infrastructure and utility should be coordinated with the hierarchy level; and function of town. In conurbation areas, the supply of utilities such as electricity and telecommunication should be of higher standard to meet the requirements of value-added and k-economy activities. Moreover, these facilities need to have an efficient level of management and maintenance with good back-up services to reduce interruption during service.

For an efficient urban service, the main strategy is to widen its coverage and improve the quality of service by ensuring the sustainability and cost efficiently of maintenance. Major urban services such as waste collection, sewerage maintenance, drainage maintenance, cleaning and management of public places should be provided extensively and be of high quality. This will improve the quality of living of the local population as well as increase the attractiveness of the urban area. For more efficient and cost effective management of domestic effluent, the existing sewerage system needs to be improved in addition to the construction of new facilities. The involvement of the local community needs to be encouraged to assist the local authority in administering and managing the urban area. Figure 3 shows how to break the spiral effect of inefficient urban governance in Kuala Lumpur City-Region development. Meanwhile figure 4 shows the effect of efficient urban governance to Kuala Lumpur City-Region development.

\section{Conclusion}

The $9^{\text {th }}$ Malaysia Plan period witnessed a renewed commitment by the government to promote good governance and will be continued with Government taking steps to enhance the integrity, transparency and accountability of the public and private sectors and further improve the level of good governance. These measures will help address corruption, reduce wastage and the cost of doing business as well as increase the efficiency of public service delivery and corporate sector. These gains from good governance will make Malaysia more competitive and attractive to investors and facilitate the achievement of the nation's development goals. The scope of efforts to enhance the public sector delivery system encompassed land administration, services of local authorities, investment facilitation, quality management, performance measurement, consolidated licenses and permits, improvements in counter services, management of public complaints, reduction of bureaucratic red tape and ICT development.

The commitment to enhance the efficiency and effectiveness of the public service delivery system will continue in order to reduce the cost of doing business, encourage private investment and positively influence investor perceptions about Malaysia as a preferred destination for trade and investment. Many challenges faces the Malaysia's city regions in this new millennium, it is importance of efficiency in urban governance is eminent in administration of developing city. 
Governance has given greater attention not only in public administration but also in the operations of private businesses. The task to turn urbanisation issues being emphasized by the government, among others, are urban poverty, the rising crime rate, solid waste disposal, housing for the poor, environmental protection, pollution, property market etc. These issues need to be tackled holistically to ensure the role of urban centre as the engine of economic growth will be continuously maintained and enhanced.

City-region need to be governed efficiently to promote a sustainable and conducive environment as a place of work and living. At the same time, the uniqueness of town should also be preserved to maintain its image and distinct identity. City-region is a catalyst and contributor towards the national economic growth, a centre for innovation and entrepreneurship and a source for high social services. Efficient urban governance will help to generate a competitive national development. Therefore, development potentials that exist in city-region should be continuously adopted and supported as a place for investment and providing services of a high level.

The pressure to create employment will be more intense in the conurbation which is expected to encounter competition from other cities worldwide due to globalisation and trade liberalisation. This is because the city-region is anticipated to lead the nation in securing foreign investment, and in turn become competitive centres to attract investors and buy property in city-region. Thus, one of the challenges of the urban economy is to turn city-region into the hub of property market for investment and commercial centres. It should have the capacity-region to attract foreign and local investment and trade in order to achieve a viable economy and provide adequate employment opportunities. With the rapid pace of urbanisation by 2020 , urban governance is faced with various complex challenges ahead. These challenges require that the respective parties be more focused in undertaking each and every responsibility in urban development.

\section{References}

Andersen, H T. (2001). The new urban politics of Europe: the areabased approach to regeneration policy. In Governing European Cities; Social Fragmentation, Social Exclusion and Urban Governance, (eds.) H T Andersen and R Van Kempen. pp. 233-253. Ashgate, Aldershot.

Bevir, M. (2007). Encyclopedia of governance Vol. 1 and II. University of California, Berkeley USA. Sage Publication. Bingham, L. B. (2006). The new urban governance: Processes for engaging citizens and stakeholders. Review of Policy Research, Vol. 23, No 4, $815-826$.

Campbell, B.C. (1995). The growth of American government: Governance from the Cleveland Era to the present. Indiana University Press, Bloomington.

Castells, M. (2001). The network society: A cross-cultural perspective. Edward Elgar Publishing Limited.

Communities and Local Government Department. (2003). Delivering Efficiency in Local Services. United Kingdom, p 7-9.

Companion to Economic Geography. Oxford: Blackwell Publishers, 359-376.

Dekker, K and Van Kempen, R. (2004a). Governance arrangements focusing on social cohesion: the Big Cities Policies in The Hague. The Netherlands. Eura-Eurocities paper, 28-11- 2003.

Dekker, K and Van Kempen, R. (2004b). Urban governance within the big cities policy. Cities, 21(2), 109-117.

Federal Department of Town and Country Planning of Peninsular Malaysia, (2004). National Physical Plan.

Federal Department of Town and Country Planning of Peninsular Malaysia. (2006). National Urbanisation Policy.

Garcia, M. (2006). Citizenship practices and urban governance in European cities. Urban Studies, Vol. 43, No. 4, 745-765.

Jessop, B. (1997). Governance of complexity and the complexity of governance: Preliminary remarks on some problems and limits of economic guidance. In A. Amin, \& J. Hausner (Eds.), Beyond market and hierarchy: Interactive governance and social complexity (pp. 95-108). Cheltenham: Edward Elgar.

Kooiman, J. (Ed.). (1993). Modern governance —New society government interactions. London: Sage.

Kuala Lumpur City Hall. (2003). Kuala Lumpur Structure Plan 2020.

Kuala Lumpur City Hall. (2006). Draft Kuala Lumpur City Plan 2020.

Mehta, D. (1998). Urban Governance: Lessons from Best Practices in Asia. UMP-Asia Occasional Paper No. 40.

OECD. (2006). The governance of metro-regions. OECD Territorial Review: Competitive cities in global economy: 156 -244 .

Painter, J. (2000). State and Governance. In: Sheppard, E. and Barnes, T. J. (eds.) A. 
Peters, G. B. (1996). The future of governing: Four emerging models. Lawrence: Kansas University Press. Phares, D. (2004). Governance or government in metro areas: Introduction. In D. Phares (Ed.), Metropolitan governance without metropolitan government? (pp. 1-6). Aldershot: Ashgate.

Pierre, J. (Ed.). (1998). Partnerships in urban governance-European and American experience. London: Macmillan.

Rhodes, R. (1996). The new governance: Governing without government. Political Studies, 44, $652-657$.

Rhodes, R. (2000). Governance and public administration. In J. Pierre (Ed.), Debating governance-Authority, steering and democracy (pp. 54-90). Oxford: Oxford University Press.

Scott, A.J. (2001). Global City-Regions: Trends, Theory, Policy. United Kingdom: Oxford University Press.

Simon, H. (1976). Administrative Behaviour. New York Press, p 30-31.

Stoker, G. (1998). Public-private partnerships in urban governance. In: J. Pierre, Editor, Partnerships in urban governance_European and American experience, Macmillan, London (1998): 34-51.

Taylor, P. J. (2004). World city network: A global urban analysis. New York, Canada: Routledge.

The International Bank of Reconstruction and Development. (2001). Annual Report.

The United Nations Educational, Scientific and Cultural Organization (UNESCO). (2006). Urban policies and the right to the city: local governance, urban democracy and citizenship 3rd working meeting of UN-HABITAT/UNESCO research group.

The Urban Governance Initiative (UNDP-TUGI). (2003). Environment and Urbanization, Vol. 15, No. 1, $159-169$.

United Nations Centre for Human Settlements (UN-HABITAT). (2001). Cities in globalizing world: Global report on human settlements. Earthscan.

Vranken, J, De Decker, P, and Van Nieuwenhuyze, I. (2003). Social inclusion, urban governance and sustainability. Towards a conceptual framework for the UGIS Research Project.

Table 1. A summary of definition of governance

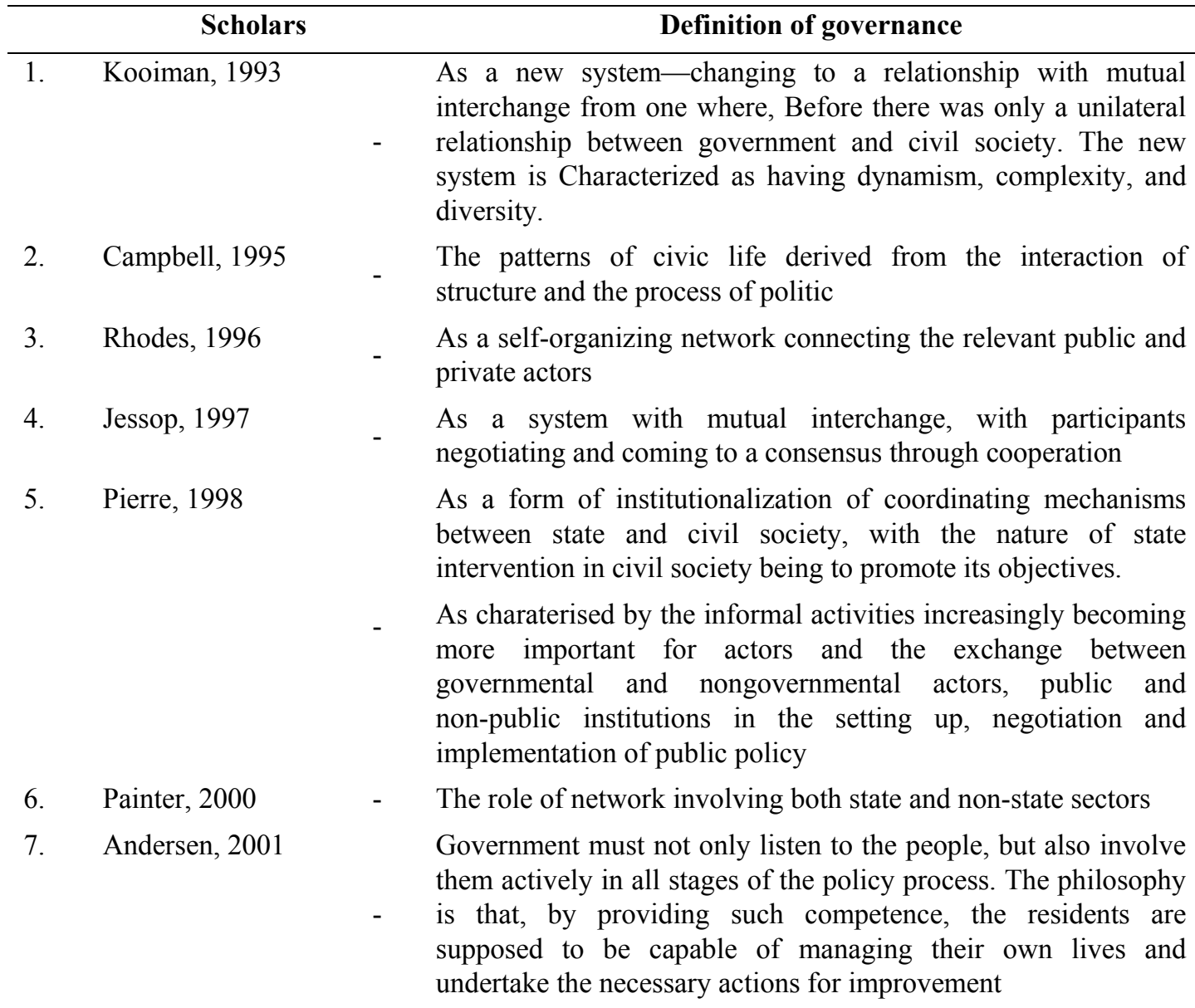

8. UN-Habitat, 2001 The sum of the ways through which individuals and institutions 
(public and private) plan and manage their common affairs. It is equally important to strengthen the linkages between local governments and the civil society so as to bring in transparency and accountability in public service. And it becomes imperative to put in place institutional structures and mechanisms that provide all urban citizens, especially the poor, vulnerable and marginalised, a voice in the development decision-making processes.

9. Garcia, 2006

A negotiation mechanism for formulating and implementing policy that actively seeks the involvement of stakeholders and civil society organizations besides governmental bodies and experts.

10. Bevir, 2007

Describe the change in the nature and role of the state following the public-sector reforms that led to a shift from a hierarchic bureaucracy towards a greater use of markets, quasi-markets and networks especially in the delivery of public services.

Table 2. A summary of definition and application of urban governance

\begin{tabular}{lll}
\hline No & Scholar & Definition of urban governance \\
\hline $1 . \quad$ Stoker, 1998 & As an outcome that is visible to a \\
& citizen is a key feature that allows \\
& empirical tests of the city as a \\
& place or as a sustained \\
& achievement of performances. A \\
& form of co-governing generated \\
& for a specific place such as a \\
& city-region.
\end{tabular}

2. Mehta, 1998

3. The International

Bank of

Reconstruction and Development, 2001

4. Dekker \& Van
Kempen, 2004
As the concept of networking of one city with other cities or with key actors such as firms, labor unions and business associations, but also other states.
Exercise of power to manage a city's economic and social development. Developing policies and approaches to meet community needs with the involvement of the community in the process

As relies on self-organizing networks and bottom-up approaches, and considers the

\section{Application}

In fact, the contemporary urban environment with its multitudinous urban issues is too complex and diverse to be addressed by municipal government independently. The common view now is that it is time to solve urban issues by building up an urban governance structure with stakeholder's participation.

A number of indicators of networking such as the number of inter-city, regional, and international networks as well as the extent of technological interchange and collaboration.

Measures such as presence of business sector initiatives to improve efficiency of local government functioning, as well as the degree to which implementation of policies and incentive schemes exist to encourage private sector participation in development. Involving the community in identifying their wants and needs - this implies that the city government will uphold democratic processes and be accountable to the people of the city

The type of participation in urban governance is substantial and positive rather than formal 


\section{UNESCO, 2006}

\section{OECD, 2006}

7. Bingham, 2006

1. Stoker, 1998

2. Mehta, 1998 citizen as actors, participating to make important decisions for the administration and process of urban policy

As the processes that steer and take into account the various links between stakeholders, local authorities and citizens.

As the roles and responsibilities of different levels of government operating in metropolitan regions, intergovernmental co-ordination and new relationship with the private sector and civil society.

As ways to engage citizens in urban policy decisions. These processes let people demonstrate that they have the potential to engage in dialogue and reach consensus on what is the best for their community.

As an outcome that is visible to a citizen is a key feature that allows empirical tests of the city as a place or as a sustained achievement of performances. A form of co-governing generated for a specific place such as a city-region.

As the concept of networking of one city with other cities or with key actors such as firms, labor unions and business associations, but also other states. and negative. The relationship among participants works in a horizontal structure of partnerships and networks with those in authority and having accountability.

It involves bottom-up and top-down strategies to favor active participation of communities concerned, negotiation among actors, transparent decision-making mechanisms, and innovation in strategies of urban management policies.

There is a strong interest in developing an adequate formula that will respond to metropolitan challenges now visible everywhere.

The integration of reasoned discussions by the citizens and other residents into the decision-making of public representatives, especially when these approaches are embedded in the workings of local government over time.

In fact, the contemporary urban environment with its multitudinous urban issues is too complex and diverse to be addressed by municipal government independently. The common view now is that it is time to solve urban issues by building up an urban governance structure with stakeholder's participation.

A number of indicators of networking such as the number of inter-city, regional, and international networks as well as the extent of technological interchange and collaboration. Measures such as presence of business sector initiatives to improve efficiency of local government functioning, as well as the degree to which implementation of policies and incentive schemes exist to encourage private sector participation in development.

Involving the community in identifying their wants and needs - this implies that the city 
Development, 2001

4. Dekker \& Van Kempen, 2004

5. UNESCO, 2006

6. OECD, 2006

7. Bingham, 2006 and approaches to meet community needs with the involvement of the community in the process

As relies on self-organizing networks and bottom-up approaches, and considers the citizen as actors, participating to make important decisions for the administration and process of urban policy

As the processes that steer and take into account the various links between stakeholders, local authorities and citizens.

As the roles and responsibilities of different levels of government operating in metropolitan regions, intergovernmental co-ordination and new relationship with the private sector and civil society. As ways to engage citizens in urban policy decisions. These processes let people demonstrate that they have the potential to engage in dialogue and reach consensus on what is the best for their community. government will uphold democratic processes and be accountable to the people of the city

The type of participation in urban governance is substantial and positive rather than formal and negative. The relationship among participants works in a horizontal structure of partnerships and networks with those in authority and having accountability.

It involves bottom-up and top-down strategies to favor active participation of communities concerned, negotiation among actors, transparent decision-making mechanisms, and innovation in strategies of urban management policies.

There is a strong interest in developing an adequate formula that will respond to metropolitan challenges now visible everywhere.

The integration of reasoned discussions by the citizens and other residents into the decision-making of public representatives, especially when these approaches are embedded in the workings of local government over time. 


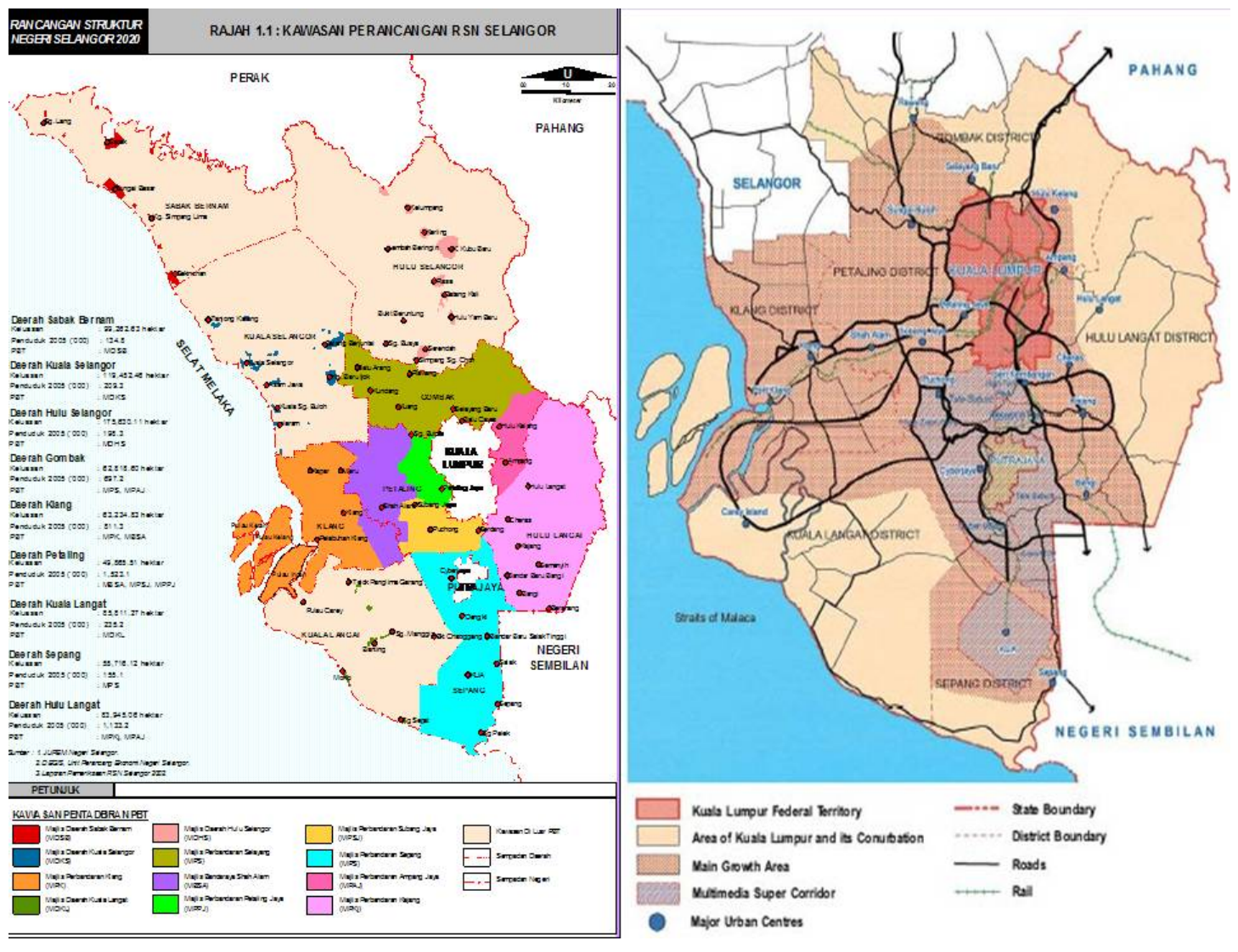

Figure 1. The location of Kuala Lumpur City-Region 


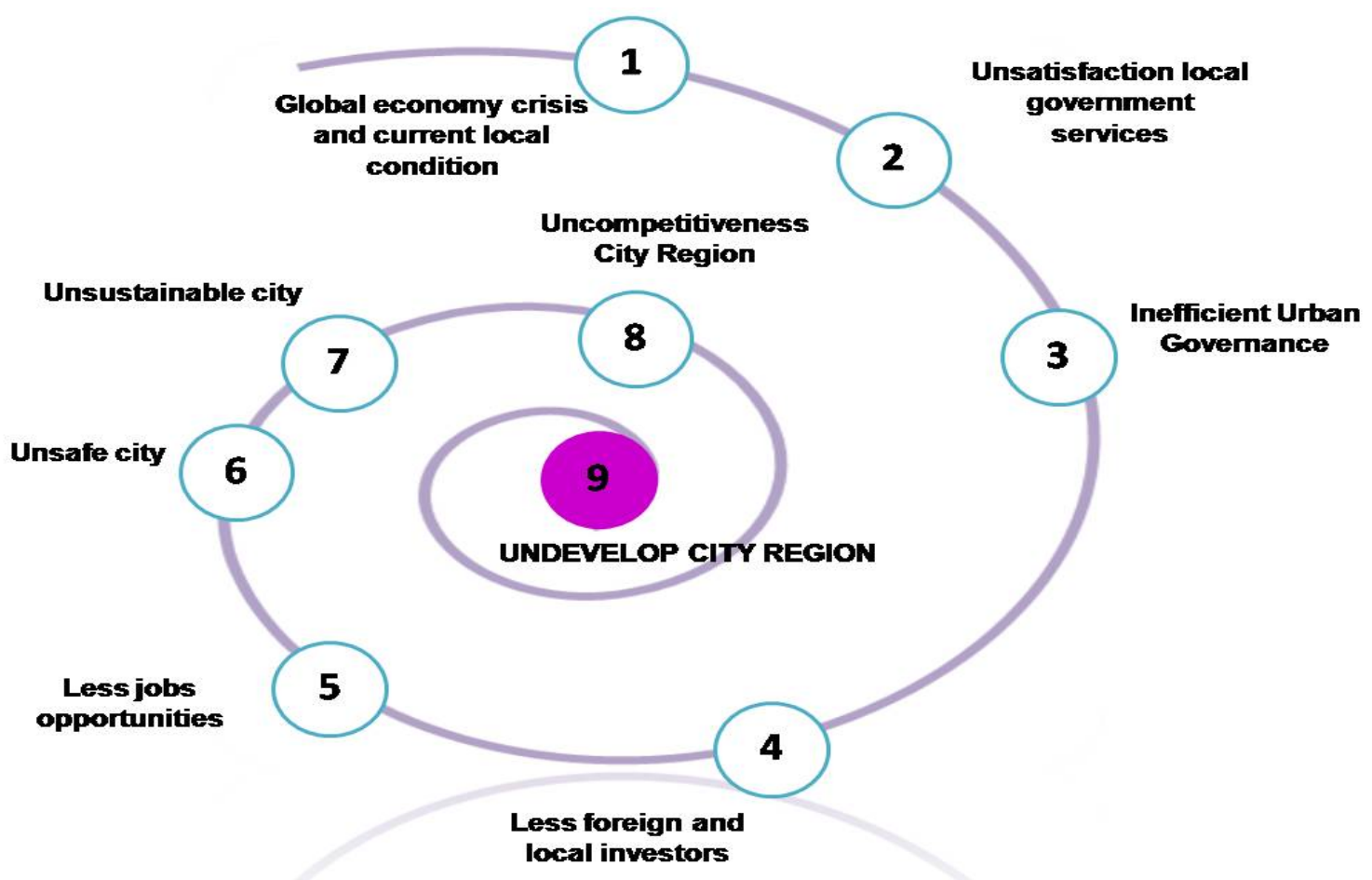

Figure 2. The spiral effect of inefficient urban governance in Kuala Lumpur city-region development

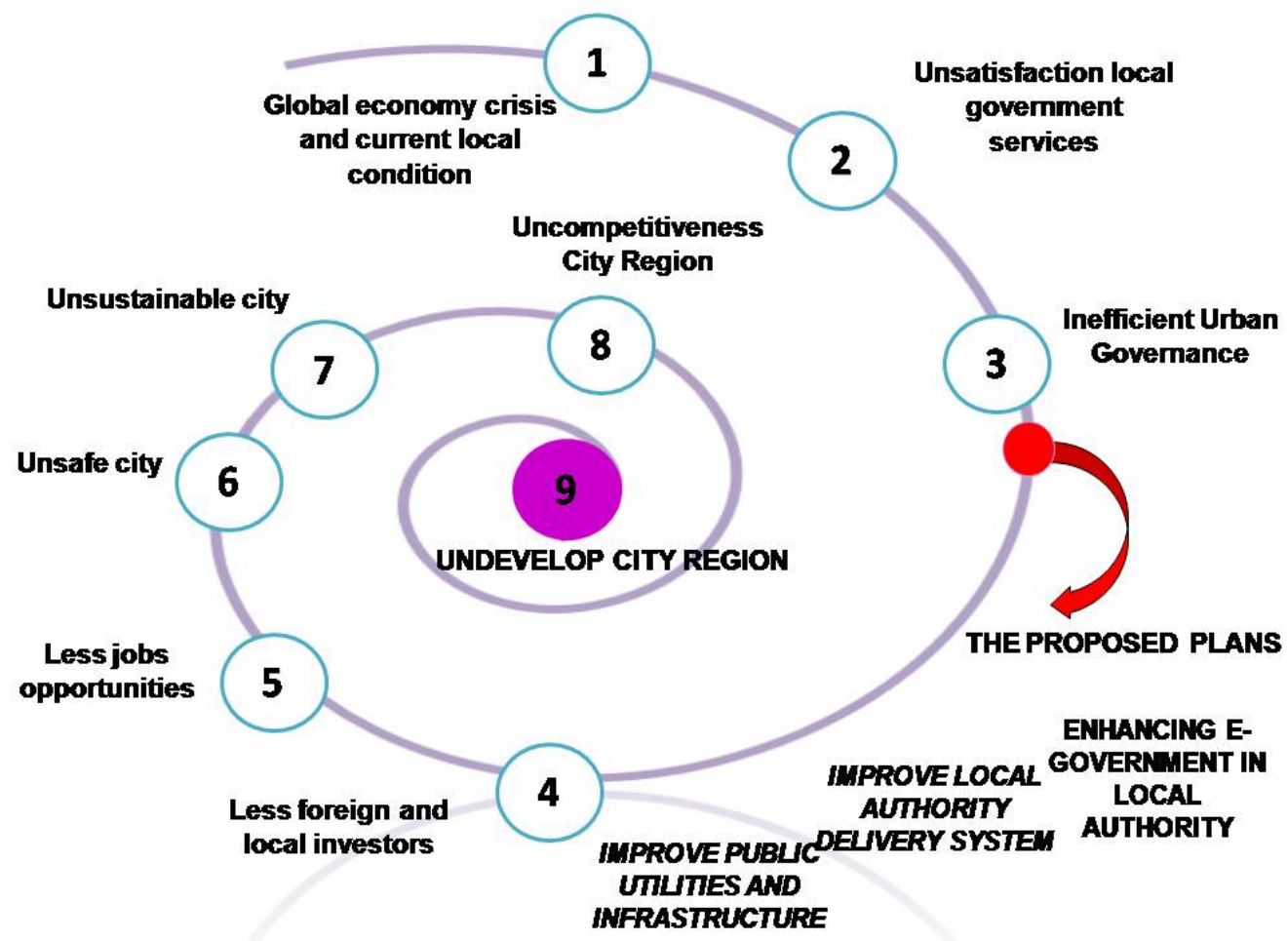

Figure 3. How to break the spiral effect of inefficient urban governance in Kuala Lumpur city-region development 


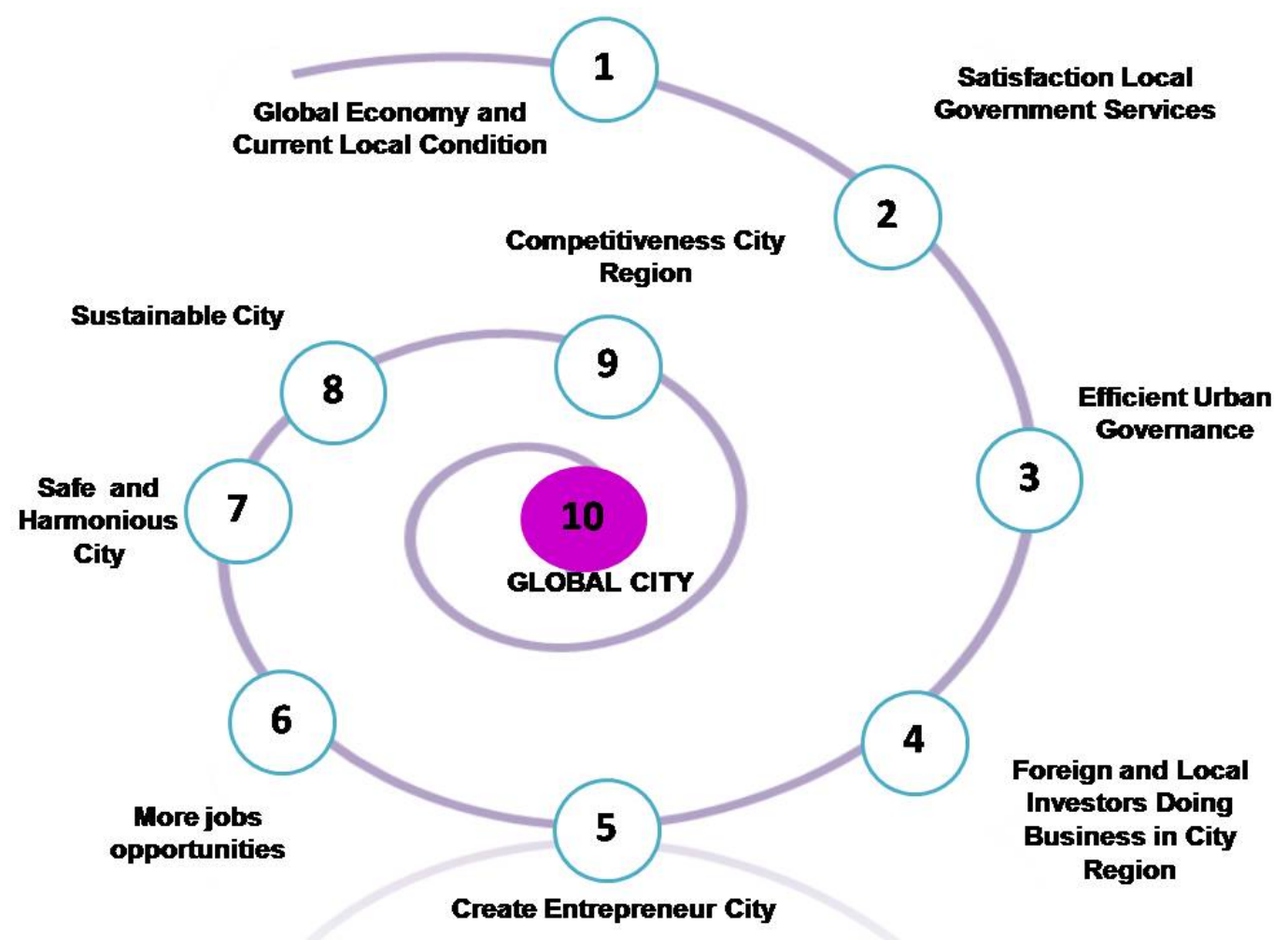

Figure 4. The effect of efficient urban governance to Kuala Lumpur city-region development 